OPEN ACCESS

Edited by:

Danilo Bilches Medinas,

University of Chile, Chile

Reviewed by:

Karen Schmitt,

Central Institute of Mental Health (ZI),

Germany

Merja Jaronen,

University of Eastern Finland, Finland

*Correspondence:

Mario Sanhueza

mario.sanhueza@umayor.cl

Received: 10 July 2020

Accepted: 24 August 2020

Published: 11 September 2020

Citation:

Muñoz-Carvajal F and Sanhueza M (2020) The Mitochondrial Unfolded Protein Response: A Hinge Between Healthy and Pathological Aging.

Front. Aging Neurosci. 12:581849. doi: 10.3389/fnagi.2020.581849

\section{The Mitochondrial Unfolded Protein Response: A Hinge Between Healthy and Pathological Aging}

\author{
Francisco Muñoz-Carvajal ${ }^{1,2,3}$ and Mario Sanhueza ${ }^{1,2 *}$

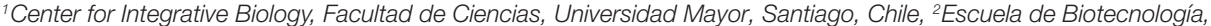 \\ Facultad de Ciencias, Universidad Mayor, Santiago, Chile, ${ }^{3}$ Fondap Geroscience Center for Brain Health and Metabolism, \\ Santiago, Chile
}

Aging is the time-dependent functional decline that increases the vulnerability to different forms of stress, constituting the major risk factor for the development of neurodegenerative diseases. Dysfunctional mitochondria significantly contribute to aging phenotypes, accumulating particularly in post-mitotic cells, including neurons. To cope with deleterious effects, mitochondria feature different mechanisms for quality control. One such mechanism is the mitochondrial unfolded protein response (UPR $\left.{ }^{\mathrm{MT}}\right)$, which corresponds to the transcriptional activation of mitochondrial chaperones, proteases, and antioxidant enzymes to repair defective mitochondria. Transcription of target UPR ${ }^{\mathrm{MT}}$ genes is epigenetically regulated by Histone 3-specific methylation. Age-dependency of this regulation could explain a differential UPR ${ }^{\mathrm{MT}}$ activity in early developmental stages or aged organisms. At the same time, precise tuning of mitochondrial stress responses is crucial for maintaining neuronal homeostasis. However, compared to other mitochondrial and stress response programs, the role of UPR ${ }^{\mathrm{MT}}$ in neurodegenerative disease is barely understood and studies in this topic are just emerging. In this review, we document the reported evidence characterizing the evolutionarily conserved regulation of the UPR ${ }^{\mathrm{MT}}$ and summarize the recent advances in understanding the role of the pathway in neurodegenerative diseases and aging.

Keywords: mitochondrial unfolded protein response, neurodegenerative diseases, aging, mitochondria, epigenetic regulation, stress response

\section{UPR ${ }^{M T}$ MACHINERY AND MITOCHONDRIAL HOMEOSTASIS REGULATION}

Mitochondria are the main energy producers within the cell and the coordinators of several pathways that control essential metabolites, which include not only ATP and $\mathrm{NAD}^{+}$, but also acetyl-CoA and S-adenosyl methionine for protein acetylation and methylation, respectively (Teperino et al., 2010; Menzies et al., 2016). Mitochondria are unique in that they have an independent genome (mtDNA), which encodes 2 rRNAs, 22 tRNAs, and 13 proteins that constitute the OXPHOS complexes (Wallace and Chalkia, 2013). Remaining mitochondrial proteins are encoded in the nucleus, so the function of the organelle heavily depends on the coordinated regulation of nuclear and mitochondrial genomes (Couvillion et al., 2016). Imbalances in protein expression in any of these two sources activate 
an anterograde regulation of mitochondrial function (from the nucleus towards mitochondria) that adjusts its activity to match cellular needs (Cui et al., 2006; Kaarniranta et al., 2018). Mitochondria can also control the expression of nuclear genes through a retrograde regulatory mechanism (Lin and Haynes, 2016). This bidirectional communication between mitochondria and the nucleus forms a molecular network that maintains cellular homeostasis. Part of the network that synchronizes the cellular adaptation to a variety of stressors is termed the mitochondrial unfolded protein response $\left(\mathrm{UPR}^{\mathrm{MT}}\right)$. Thus, $\mathrm{UPR}^{\mathrm{MT}}$ is the transcriptional program that stabilizes mitochondrial homeostasis and reduces misfolded protein amount in the organelle, increasing the mitochondrial response capability to stress stimuli (reviewed in Jensen and Jasper, 2014; Shpilka and Haynes, 2018; Gomez and Germain, 2019; Tran and Van Aken, 2020). Known activators of UPR ${ }^{\mathrm{MT}}$ include the impairment of the Electron Transport Chain (ETC), alteration of mitochondrial dynamics, accumulation of unfolded proteins, deletion of mitochondrial DNA (mtDNA), inhibition of mitochondrial chaperones or proteases, and the increase of reactive oxygen species (ROS) levels (Nargund et al., 2012; Pimenta de Castro et al., 2012; Runkel et al., 2013; Qureshi et al., 2017). Despite the mechanisms underlying the $\mathrm{UPR}^{\mathrm{MT}}$ are less understood than endoplasmic reticulum UPR (Hetz et al., 2020), this mitochondrial stress pathway is emerging as an important response that guarantees the organelle function.

$\mathrm{UPR}^{\mathrm{MT}}$ was originally observed in mammalian cells, where mitochondrial stress was induced by mtDNA deletions (Martinus et al., 1996) and by aggregation of mutant ornithine transcarboxylase ( $\triangle$ OTC) (Zhao et al., 2002). Both stress stimuli upregulated the expression of mitochondrial chaperones Hsp60, Hsp10 under the control of the transcription factor CHOP (Zhao et al., 2002; Horibe and Hoogenraad, 2007). Three nuclear components were then identified in C. elegans as $\mathrm{UPR}^{\mathrm{MT}}$ regulators: ATFS-1, DVE-1, and UBL-5. These proteins are part of the UPR ${ }^{\mathrm{MT}}$-ATF5 axis, an ATFS-1/ATF5 dependent response that is the most characterized $\mathrm{UPR}^{\mathrm{MT}}$ pathway (Table $\mathbf{1}$, Kenny and Germain, 2017; Ji et al., 2020). ATFS-1, a leucine zipper protein, carries a nuclear localization sequence and a mitochondrial targeting sequence. Under mitochondrial stress, ATFS-1 normal transport towards mitochondria is blocked and translocates instead to the nucleus where it interacts with DVE-1 and UBL-5 (Figure 1; Nargund et al., 2012, 2015). In mammals, the CHOP target ATF5 was identified as the functional ortholog for ATFS-1, which also contains targeting sequences for mitochondria and nucleus and upregulates $\mathrm{UPR}^{\mathrm{MT}}$ genes (Teske et al., 2013; Fiorese et al., 2016). On the other hand, DVE-1 is a DNA binding protein that together with its coregulator UBL-5, interacts with chromatin regions to maintain an ATFS-1-dependent active transcription of UPR ${ }^{\mathrm{MT}}$ related genes (Benedetti et al., 2006; Haynes et al., 2007; Tian et al., 2016). The coordinated action of these three proteins upregulates the expression of mitochondrial chaperones hsp-60, hsp-6, and protease clpp-1 (Table 1, Haynes and Ron, 2010).

Two other pathways have been associated with this stress response (Figure 1). The $\mathrm{UPR}^{\mathrm{MT}}$-ER $\alpha$ axis, a pathway dependent on the activation of the estrogen receptor $\alpha(\mathrm{ER} \alpha)$, was described as associated with the accumulation of proteins in the mitochondrial intermembrane space (Papa and Germain, 2011). Mitochondrial stress and ROS production trigger the phosphorylation of the protein kinase AKT and consequently, the activation of ER $\alpha$. This cascade increases the transcription of protease HTRA2 and the mitochondrial biogenesis regulator NFR1, which translates in an increased proteasome activity independent of activation of the UPR ${ }^{\mathrm{MT}}$-ATF5 axis (Table 1, Papa and Germain, 2011). Finally, the $\mathrm{UPR}^{\mathrm{MT}}$-SIRT3 axis is based on the activation of Sirtuin 3 that modulates the expression of SOD1, SOD2, and catalase, through activation of FOXO (Papa and Germain, 2014; Kenny et al., 2017). The UPR ${ }^{\mathrm{MT}}$ SIRT3 axis has been validated also in worms and mammalian cells, supporting the high evolutionary conservation of the pathway (Mouchiroud et al., 2013). Importantly, both ER $\alpha$ and SIRT3-UPR ${ }^{\mathrm{MT}}$ axes work independently of CHOP (Papa and Germain, 2014), upholding the idea of three parallel paths coordinating the same stress response (Figure 1).

Chromatin remodeling has been shown to play a central role in $\mathrm{UPR}^{\mathrm{MT}}$ regulation. Histone 3 is a target for methylation catalyzed specifically by methyltransferase MET-2 in C. elegans (ortholog of human SETDB1). Activation of $\mathrm{UPR}^{\mathrm{MT}}$ requires the dimethylation of lysine 3 of histone 3 (H3K9), which translates into a compacted and overall silenced chromatin state. At the same time although, other chromatin portions remain loose, favoring the binding of $\mathrm{UPR}^{\mathrm{MT}}$ regulators such as DVE-1 (Tian et al., 2016). Also required for $\mathrm{UPR}^{\mathrm{MT}}$ activation are the conserved demethylases JMJD-3.1 and JMJD-1.2, which reduce the chromatin compaction by removing methylation from H3K9 and H3K27 (Figure 1; Merkwirth et al., 2016; Sobue et al., 2017). Interestingly, chromatin remodeling acts independently of ATFS-1, as its downregulation does not affect the nuclear localization of DVE-1 (Tian et al., 2016). It is known that besides genes encoding chaperones and proteases, UPR ${ }^{\mathrm{MT}}$ activation increases the expression of glycolysis and amino acid catabolism genes, and represses TCA-cycle and OXPHOS encoding genes (Nargund et al., 2015; Gitschlag et al., 2016; Lin and Haynes, 2016). To date, it is not clear whether $\mathrm{UPR}^{\mathrm{MT}}$ can activate any other quality control mechanism such as mitochondrial fission, fusion, and mitophagy. It has been reported, however, that the same mitochondrial stressors can activate mitophagy and UPR $^{\mathrm{MT}}$ (Nargund et al., 2012; Pimenta de Castro et al., 2012; Jin and Youle, 2013; Runkel et al., 2013; Lin et al., 2016). Organisms that have adapted after constant exposure to low doses of these stressors (misregulation of ETC components and low doses of the $\mathrm{UPR}^{\mathrm{MT}}$ activator paraquat) exhibit a hormetic phenotype as they show increased longevity despite their mild mitochondrial dysfunction (Yoneda et al., 2004; Owusu-Ansah et al., 2013). This homeostatic regulation is particularly important in post-mitotic cells such as neurons.

\section{THE ROLE AND REGULATION OF UPR ${ }^{\mathrm{MT}}$ IN AGING}

Aging is defined as the time-dependent functional decline that increases vulnerability to different forms of stress, ultimately 
TABLE 1 | Mitochondrial UPR regulators and their function in conserved species.

\begin{tabular}{|c|c|c|c|c|c|c|}
\hline Name & CE & DM & MM & HS & Function & References \\
\hline \multicolumn{7}{|l|}{ UPR $^{\mathrm{MT}}$-ATF5 axis } \\
\hline Activating Transcription Factor 5 & Atfs- 1 & $\mathrm{crc}$ & Atf5 & ATF5 & $\begin{array}{l}\text { Transcription factor with basic leucine zipper domain. } \\
\text { Carries an MTS in the N-term and an NLS in the C-term. }\end{array}$ & $\begin{array}{l}\text { Yoneda et al. (2004), } \\
\text { Nargund et al. (2012), } \\
\text { Fiorese et al. (2016) and Wu } \\
\text { et al. (2018) }\end{array}$ \\
\hline $\begin{array}{l}\text { Special AT-Rich Sequence-Binding } \\
\text { Protein } 2\end{array}$ & $d v e$ & DVE & Satb2 & SATB2 & $\begin{array}{l}\text { DNA binding protein. Stabilizes open chromatin for } \\
\text { UPR } \\
\text { MT } \text {-associated transcription. }\end{array}$ & $\begin{array}{l}\text { Haynes et al. (2007) and } \\
\text { Tian et al. (2016) }\end{array}$ \\
\hline Ubiquitin Like 5 & UBL-5 & ubl & Ubl5 & UBL5 & $\begin{array}{l}\text { Protein binding. Binds DVE to activate transcription of } \\
\text { Hsp60 }\end{array}$ & Benedetti et al. (2006) \\
\hline $\begin{array}{l}\text { ATP Binding Cassette Subfamily B } \\
\text { Member } 10\end{array}$ & haf-1 & CG3156 & ABCB10 & ABCB10 & $\begin{array}{l}\text { Mitochondrial inner membrane transporter. Exports } \\
\text { peptides from the matrix. }\end{array}$ & $\begin{array}{l}\text { Haynes and Ron (2010) } \\
\text { and Yano (2017) }\end{array}$ \\
\hline $\begin{array}{l}\text { Caseinolytic Mitochondrial Matrix } \\
\text { Peptidase Proteolytic }\end{array}$ & clpp-1 & $\mathrm{ClpP}$ & ClpP & CLPP & $\begin{array}{l}\text { Mitochondrial ATP-dependent protease. Its attenuation } \\
\text { reduces the UPR }{ }^{\mathrm{MT}} \text { activation and the formation of the } \\
\text { UBL/DVE complex. }\end{array}$ & $\begin{array}{l}\text { Haynes et al. (2007) and } \\
\text { Al-Furoukh et al. (2015) }\end{array}$ \\
\hline $\begin{array}{l}\text { Translocase of Inner Mitochondrial } \\
\text { Membrane } 23\end{array}$ & timm-23 & Tim23 & Timm23 & TIMM23 & $\begin{array}{l}\text { Protein transmembrane transporter. Required for full } \\
\text { induction of UPR }\end{array}$ & Rainbolt et al. (2013) \\
\hline Lon Peptidase 1 & , lonp-1 & Lon & Lonp1 & LONP1 & $\begin{array}{l}\text { Mitochondrial protease. Degrades ATFS-1 when imported } \\
\text { to mitochondria under stress conditions. }\end{array}$ & Nargund et al. (2012) \\
\hline $\begin{array}{l}\text { Heat Shock Protein Family D } \\
\text { (Hsp60) Member } 1\end{array}$ & hsp-60 & $\begin{array}{l}\text { Hsp60A } \\
\text { Hsp60B } \\
\text { Hsp60C }\end{array}$ & Hspd1 & HSPD1 & $\begin{array}{l}\text { Mitochondrial heat-shock protease. Upregulated upon } \\
\text { mitochondrial stress. }\end{array}$ & $\begin{array}{l}\text { Zhao et al. (2002), Yoneda } \\
\text { et al. (2004), Haynes et al. } \\
\text { (2007) and Owusu-Ansah } \\
\text { et al. (2013) }\end{array}$ \\
\hline $\begin{array}{l}\text { Heat Shock Protein Family A } \\
\text { (Hsp70) Member } 9\end{array}$ & hsp-6 & Hsc70-5 & Hspa9 & HSPA9 & $\begin{array}{l}\text { Mitochondrial heat-shock protease. More sensitive to } \\
\text { oxidative stress than unfolded protein stress. }\end{array}$ & $\begin{array}{l}\text { Yoneda et al. (2004), } \\
\text { Benedetti et al. (2006) and } \\
\text { Merkwirth et al. (2016) }\end{array}$ \\
\hline \multicolumn{7}{|l|}{ UPR $^{M T}$ - ER $\alpha$ axis } \\
\hline Estrogen Receptor 1 & nhr-107 & ERR & Esr1 & ESR1 & $\begin{array}{l}\text { Ligand-activated transcription factor. Regulates the } \\
\text { expression of Htra2 and NRF1 after Akt phosphorylation. }\end{array}$ & $\begin{array}{l}\text { Papa and Germain (2011) } \\
\text { and Riar et al. (2017) }\end{array}$ \\
\hline HtrA Serine Peptidase 2 & psmd-9 & $\mathrm{HtrA2}$ & $\mathrm{HtrA} 2$ & HTRA2 & $\begin{array}{l}\text { Serine protease. Protein import checkpoint in IMS. } \\
\text { Increased expression upon stress. }\end{array}$ & Papa and Germain (2011) \\
\hline \multicolumn{7}{|l|}{ UPR MT - SIRT3 axis } \\
\hline Sirtuin 3 & Sir-2.1 & Sirt2 & Sirt3 & SIRT3 & $\begin{array}{l}\mathrm{NAD}^{+} \text {dependent deacetylase. Regulates the activity of } \\
\text { FOXO3 upon oxidative stress in the mitochondria. }\end{array}$ & $\begin{array}{l}\text { Mouchiroud et al. (2013); } \\
\text { Papa and Germain (2014); } \\
\text { Gariani et al. (2016) and } \\
\text { Kenny et al. (2017) }\end{array}$ \\
\hline Forkhead box & daf-16 & foxo & Foxo3 & $\mathrm{FOXO3}$ & $\begin{array}{l}\text { Transcription factor. Translocate to the nucleus to activate } \\
\text { transcription of SOD1, SOD2, and Catalase. }\end{array}$ & $\begin{array}{l}\text { Mouchiroud et al. (2013); } \\
\text { Gariani et al. (2016) and } \\
\text { Kenny et al. (2017) }\end{array}$ \\
\hline Superoxide dismutase 1 & sod-1 & Sod & Sod1 & SOD1 & Superoxide dismutase. Soluble cytoplasmic isoenzyme. & $\begin{array}{l}\text { Mouchiroud et al. (2013); } \\
\text { Gariani et al. (2016) and } \\
\text { Kenny et al. (2017) }\end{array}$ \\
\hline Superoxide dismutase 2 & sod-2 & Sod2 & Sod2 & SOD2 & Superoxide dismutase. Mitochondrial isoenzyme. & $\begin{array}{l}\text { Mouchiroud et al. (2013); } \\
\text { Gariani et al. (2016) and } \\
\text { Kenny et al. (2017) }\end{array}$ \\
\hline
\end{tabular}




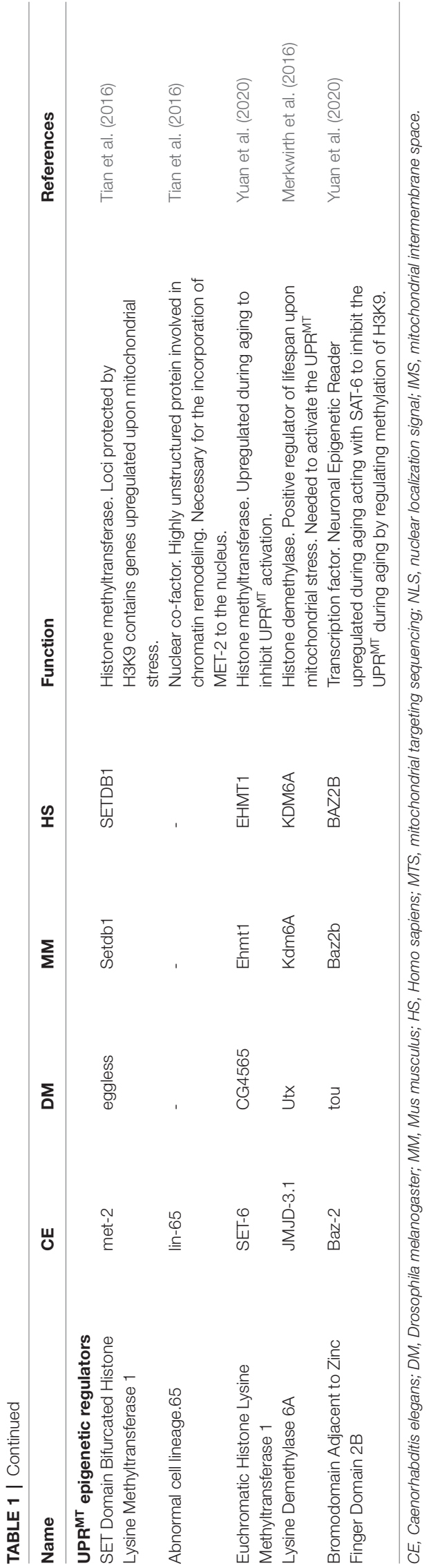

leading to death (Kennedy et al., 2014). Aging has particularly severe consequences for organs composed mostly by post-mitotic cells, such as the heart and brain (Kowald and Kirkwood, 2000; Terman et al., 2010). For instance, aging is the major risk factor for the onset of chronic, brain-related, and neurodegenerative diseases (ND). Current studies in the field introduced critical questions aiming to understand the physiological sources of time-dependent damage, the compensatory cellular responses that reestablish homeostasis, and their interconnection to find potential targets to intervene and delay aging. Seven cellular pillars of aging have been described, including among others, alterations to proteostasis, epigenetics, metabolism, and adaptation to stress (Kennedy et al., 2014). Mitochondrial dysfunction is a common factor for these events, suggesting a role of mitochondrial reparative machinery in aging progression. Furthermore, it is accepted that aging in model organisms is functionally associated with mitochondrial decline, contributing to the time-dependent tissue malfunction (Chistiakov et al., 2014; Kim et al., 2018). Therefore, activation of $\mathrm{UPR}^{\mathrm{MT}}$, as one of the mitochondrial mechanisms against different forms of agingcausing damage, could be in part bridging the adaptation to stress and other pillars of aging as proteostasis and epigenetics.

Current evidence highlights an age-dependent effect of $\mathrm{UPR}^{\mathrm{MT}}$ on lifespan. For instance, activation of $\mathrm{UPR}^{\mathrm{MT}}$ triggered by downregulation of ETC complexes I and IV promotes longevity (Dillin et al., 2002; Durieux et al., 2011; Mouchiroud et al., 2013). Histone demethylases JMJD-1.2 and JMJD3.1 mediate in part that extension, as their overexpression is sufficient to extend the lifespan of worms (Merkwirth et al., 2016). On the other hand, reducing the expression of nuclear effectors ATFS-1, UBL-5 and DVE-1, or demethylases JMJD1.2 and JMJD-3.1, suppresses the lifespan extension (Table 1, Durieux et al., 2011; Houtkooper et al., 2013; Merkwirth et al., 2016; Lan et al., 2019). It is interesting that $\mathrm{UPR}^{\mathrm{MT}}$ activation after exposure to mitochondrial stress is strongly responsive only during development and not in later stages of the lifespan (Dillin et al., 2002; Copeland et al., 2009; Durieux et al., 2011; Houtkooper et al., 2013). UPR ${ }^{\mathrm{MT}}$ appears less active in adult organisms, so there is no increased lifespan as a response to mitochondrial stressors, as observed in developmental stages in worms and flies (Dillin et al., 2002; Owusu-Ansah et al., 2013; Jensen et al., 2017).

Decreased chromatin accessibility of target $\mathrm{UPR}^{\mathrm{MT}}$ genes in aged organisms is a potential explanation for the differential $\mathrm{UPR}^{\mathrm{MT}}$ activation. This was recently confirmed in a study where the methyltransferase SET- 6 and the neuronal epigenetic reader BAZ-2, mediated specifically an age-dependent regulation of $\mathrm{UPR}^{\mathrm{MT}}$. Both proteins when overexpressed in aged worms increased the levels of $\mathrm{H} 3 \mathrm{~K} 9 \mathrm{Me} 3$, the triple methylated state of the protein, thus inhibiting $\mathrm{UPR}^{\mathrm{MT}}$ activation in the H3K9-protected loci (Figure 1). Loss of function of SET-6 or BAZ-2 increased healthspan but not longevity, a phenotype that was inhibited downregulating UBL-5 or ATFS-1 (Yuan et al., 2020). Histone 3 methylation appears then as a key epigenetic mediator for UPR ${ }^{\mathrm{MT}}$ throughout the lifespan (Merkwirth et al., 2016; Tian et al., 2016; Ono et al., 2017). Longitudinal studies have proved that $\mathrm{H} 3 \mathrm{~K} 9 \mathrm{Me} 3$ increases during aging in mice 

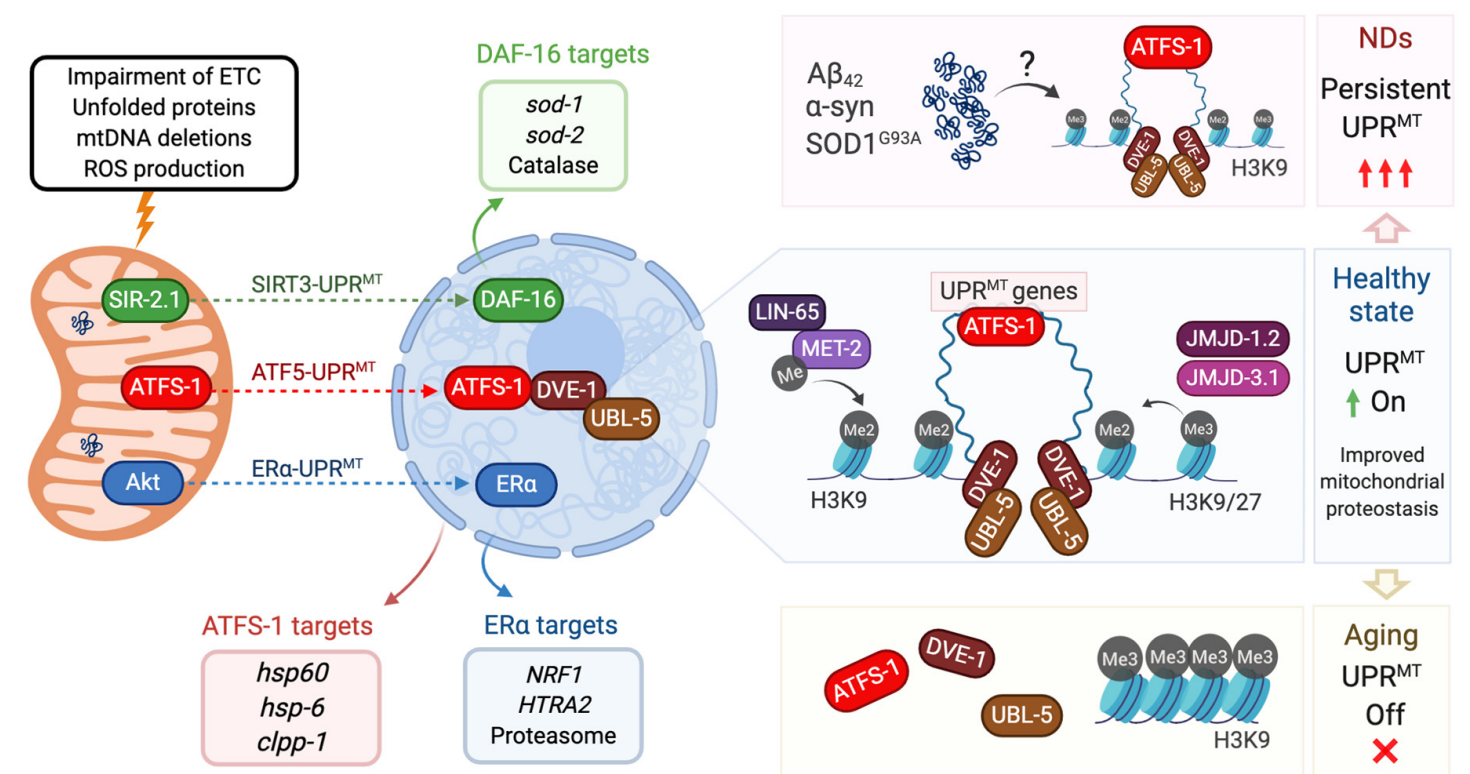

FIGURE 1 | Mitochondrial unfolded protein response (UPR) and its regulation in aging and neurodegeneration. Insults to mitochondria (top left) activate three different axes of the UPR ${ }^{\mathrm{MT}}$ program. The SIRT3-UPR ${ }^{\mathrm{MT}}$ axis (green arrow) increases the transcription of superoxide dismutases and catalase, after the activation of DAF-16/FOXO3 by the deacetylase SIR-2.1/SIRT3. In the ATF5-UPR ${ }^{\mathrm{MT}}$ axis (red arrow), the transcription factor ATFS-1/ATF5 relocalizes from mitochondria to nucleus to upregulate mitochondrial proteostasis related genes (red box) after the interaction with the chromatin stabilizers DVE-1 and UBL-5. In the ER $\alpha-U P R{ }^{\mathrm{MT}}$ axis (blue arrow) the estrogen receptor is activated by the kinase Akt, to increase the expression of the protease HTRA2 and mitochondrial biogenesis regulator NRF1. On a healthy state (center right), ATF5-UPR ${ }^{\mathrm{MT}}$ activation requires chromatin reorganization. Dimethylation of Histone 3 by MET-2, and presence of demethylases JMJD-1.2 and JMJD-3.1, allow the binding of DVE to facilitate the ATFS-1-dependent expression of UPR ${ }^{\mathrm{MT}}$ genes and improve mitochondrial proteostasis. In neurodegenerative states triggered by accumulation of $A \beta_{42}(A D), \alpha$-syn (PD) or SOD1 ${ }^{\text {G93A }}$ (ALS, top right), UPR ${ }^{M T}$ could be persistently activated, affecting mitochondria proteostasis and neuron viability. In aging cells (bottom right), Histone 3 is preferentially trimethylated, which blocks DVE and ATFS- 1 biding to compacted DNA. Lack of expression of UPR ${ }^{\mathrm{MT}}$-related genes decreases mitochondrial response to aging-causing damage. All protein names are taken from C. elegans, except the ones from the ER $\alpha$ axis, which has only been described in mammalian cells.

hippocampus, and inhibition of this methylation state was sufficient to block aging-associated cognitive decline in mice (Snigdha et al., 2016). Advanced knowledge of the loci carrying $\mathrm{UPR}^{\mathrm{MT}}$ genes on them, will contribute to further understand the lack of $\mathrm{UPR}^{\mathrm{MT}}$ activation during aging.

\section{UPR $^{M T}$ IN AGING NEURONS AND NEURODEGENERATIVE DISEASES}

Several factors influence mitochondrial homeostasis in neurons during aging, such as oxidative damage, neuronal localization, and quality control mechanisms. Compared to mitotic cells, neurons are more sensitive to the accumulation of oxidative damage and defective mitochondria (Kowald and Kirkwood, 2000; Terman et al., 2010). Neuronal unique shape, on the other hand, generates a differential mitochondrial distribution required to provide energy at specific compartments (Obashi and Okabe, 2013). Indeed, evidence shows that at nerve terminals, mitochondria are more prone to age-related dysfunction and oxidative damage compared to non-synaptic mitochondria (Lores-Arnaiz et al., 2016; Olesen et al., 2020). Importantly, aging aggravates the difference between these two populations of mitochondria (Borrás et al., 2010; Lores-Arnaiz et al., 2016). The decreased ability of neurons to renew their pool of healthy mitochondria and the lower activity of quality control mechanisms, act synergistically to trigger deleterious consequences in neurons not only in aging but also at earlier stages. In the etiology of the most prevalent ND, shared critical mitochondrial stressors include misfolded and aggregated proteins, impaired mitophagy, and oxidative stress (Niedzielska et al., 2016; Bakula and Scheibye-Knudsen, 2020; Weidling and Swerdlow, 2020). Considering also the number of ND-causative genes associated with mitochondrial dysfunction (Masters et al., 2015; Hardiman et al., 2017; Poewe et al., 2017), quality control mechanisms such as $\mathrm{UPR}^{\mathrm{MT}}$ emerge as key intervention targets for age-related diseases. However, compared to other mitochondrial response programs (Pellegrino and Haynes, 2015; Pernas and Scorrano, 2016; Misgeld and Schwarz, 2017) or even $\mathrm{UPR}^{\mathrm{ER}}$ (Hetz et al., 2020), the studies linking UPR ${ }^{\mathrm{MT}}$ and NDs are just emerging.

Parkinson's disease (PD) is caused by decreased dopamine secretion from damaged dopaminergic neurons (reviewed in Poewe et al., 2017). PD pathomechanism is strongly connected to mitochondrial dysfunction and only recently to $\mathrm{UPR}^{\mathrm{MT}}$ (Franco-Iborra et al., 2018; Chen et al., 2019). Two proteins encoded by $\mathrm{PD}$-causative genes, serine-threonine kinase PINK1 and E3 ubiquitin ligase Parkin, work together to unclutter dysfunctional mitochondria through mitophagy. PINK1 or 
Parkin downregulation induces decreased mitochondrial respiration and ATP synthesis, degeneration of dopaminergic neurons, and reduced lifespan (Zhu et al., 2013; Moisoi et al., 2014; Tufi et al., 2014; Choi et al., 2015). In C. elegans, the downregulation of their orthologs (pink-1 and $p d r-1$ ) activates $\mathrm{UPR}^{\mathrm{MT}}$ as a mitigation mechanism. Without atfs- 1 dependent $\mathrm{UPR}^{\mathrm{MT}}$ activation, lifespan decreases, and dopamine neurons degenerate (Cooper et al., 2017).

PINK1 also interacts with the ER $\alpha$ target HTRA2, mediating its phosphorylation and activation (Plun-Favreau et al., 2007). Interestingly, mutant alleles of HTRA2 were found in $\mathrm{PD}$ patients (Strauss et al., 2005; Unal Gulsuner et al., 2014).

PD pathogenesis is strongly connected to the accumulation of $\alpha$-synuclein (Poewe et al., 2017). $\alpha$ Syn $^{\mathrm{A} 53 \mathrm{~T}}$ preferentially accumulates in the mitochondria and interacts with the $\mathrm{UPR}^{\mathrm{MT}}$-regulator ClpP, suppressing its peptidase activity. Overexpression of the protease is sufficient to decrease $\alpha \operatorname{Syn}^{\mathrm{A}}{ }^{\mathrm{5} 3 \mathrm{~T}}$ associated pathology in mice ( $\mathrm{Hu}$ et al., 2019). Despite the previous evidence, reports are suggesting a toxic role of UPR ${ }^{\mathrm{MT}}$ over-activation. Expression in dopaminergic neurons of an active form of ATFS-1 lacking the mitochondrial target sequence mimics stress conditions with a constant nuclear expression of $\mathrm{UPR}^{\mathrm{MT}}$ targets. Over-activation of $\mathrm{UPR}^{\mathrm{MT}}$ shortens lifespan and promotes faulty mitochondria accumulation, a phenotype synergistically increased overexpressing mutant $\alpha \operatorname{Syn}^{\mathrm{A} 53 \mathrm{~T}}$ (Martinez et al., 2017). From the epigenetic point of view, $\alpha$-synuclein expression in Drosophila led to an upregulation of the methyltransferase EHMT2, with an overall H3K9 dimethylation effect (Sugeno et al., 2016). It would be interesting to study whether chromatin remodeling linked to the $\mathrm{H} 3 \mathrm{~K} 9 \mathrm{Me} 2$ epigenetic mark in this PD model modifies $\mathrm{UPR}^{\mathrm{MT}}$ activation as previously reported (Merkwirth et al., 2016; Tian et al., 2016).

Amyotrophic lateral sclerosis (ALS) is the most common motor neuron disease and its complex etiology is explained by the almost 30 causative genes that have been linked to familial cases (reviewed in Hardiman et al., 2017). Among these genes, mutations in the superoxide dismutase SOD1 initially unveiled a link between ALS and mitochondrial dysfunction (Rosen et al., 1993). Post-mortem samples of ALS patients show the altered activity of ETC complexes (Bowling et al., 1993), while SOD1 overexpression in transgenic mice causes dysregulated ETC activity, increased ROS production, and diminished mitochondrial $\mathrm{Ca}^{2+}$-buffering (Mattiazzi et al., 2002; Brookes et al., 2004). Mutant SOD ${ }^{\text {G93A }}$ localizes in the mitochondrial intermembrane space, which is sufficient to activate two axes of $\mathrm{UPR}^{\mathrm{MT}}$ in vivo (Gomez and Germain, 2019). CHOP is transiently activated in mice's spinal cord, followed by Akt-dependent phosphorylation of ER $\alpha$ that upregulates NRF1 and proteasome activity (Riar et al., 2017; Gomez and Germain, 2019). This is consistent with recent reports showing that $\mathrm{UPR}^{\mathrm{MT}}$ activation precedes the onset of ALS and its activity increases throughout disease progression (Pharaoh et al., 2019). Dysregulation of TDP43, another ALS causative gene, impairs mitochondria in ALS patients, suppresses ETC complex I and activates $\mathrm{UPR}^{\mathrm{MT}}$ in cellular and animal models. Downregulation of the UPR ${ }^{\mathrm{MT}}$ protease LonP1 increased TDP-43 levels, mitochondrial damage and neurodegeneration (Wang et al., 2019). A third ALS-linked mitochondrial protein is CHCHD10, which has an unknown function but its mutant aggregates in mitochondria causing proteotoxic stress, mitochondrial dysfunction and upregulation of the $\mathrm{UPR}^{\mathrm{MT}}$ regulators $\mathrm{CHOP}$ and ATF5 (Anderson et al., 2019). These reports suggest that the accumulation of ALS-associated mutant proteins in mitochondria persistently over activates $\mathrm{UPR}^{\mathrm{MT}}$, which could be triggering detrimental effects on already stressed neurons (Figure 1).

Alzheimer's disease (AD) is characterized by key neuropathological hallmarks such as the abnormal accumulation of the amyloid- $\beta$ (A $\beta$ ) peptide (reviewed in Masters et al., 2015). Evidence indicates that oxidative damage and mitochondrial dysfunction have a key role in $\mathrm{AD}$ pathogenesis (Butterfield and Halliwell, 2019; Weidling and Swerdlow, 2020), but the relationship between $\mathrm{UPR}^{\mathrm{MT}}$ and $\mathrm{AD}$ has only been recently explored. $\mathrm{A} \beta$ accumulation activates $\mathrm{UPR}^{\mathrm{MT}}$ in human cells and mice (Shen et al., 2020). In C. elegans, the sirtuin-activator resveratrol reduced the $A \beta$-induced toxicity on a Ubl-5 dependent manner, decreasing the amount of $\mathrm{A} \beta$ aggregates (Regitz et al., 2016). Further characterization of this finding could provide clues of a potential connection between the two UPR ${ }^{\mathrm{MT}}$ axes, and their association to AD. On the other hand, deficiency of the mitochondrial protease PITRM1 induces $\mathrm{UPR}^{\mathrm{MT}}$, increased $A \beta$ accumulation, and triggered $A D$-like phenotypes. These were exacerbated by pharmacological inhibition of UPR ${ }^{\mathrm{MT}}$ suggesting a protective role of the pathway on $A \beta$-associated toxicity (Pérez et al., 2020). The expression of UPR ${ }^{\mathrm{MT}}$-related genes appear highly increased in post mortem samples of the prefrontal cortex of $\mathrm{AD}$ patients (Beck et al., 2016). It would be noteworthy to determine the temporality of this increased expression to understand whether it is an early program persistently activated throughout the disease progression, or a late response triggered by an overall mitochondrial dysfunction. This is especially relevant considering that the expression of the epigenetic regulators of UPR ${ }^{\mathrm{MT}}$ EHMT1 and BAZ2B, and therefore inhibition of $\mathrm{UPR}^{\mathrm{MT}}$, correlates positively with the progression of AD (Zhang et al., 2013; Yuan et al., 2020). Therefore, future studies should try to clarify whether both inhibition and persistent activation of $\mathrm{UPR}^{\mathrm{MT}}$ contribute to ND pathomechanisms.

\section{FUTURE PERSPECTIVES}

Mitochondrial dysfunction is a hallmark of aging and age-related neurodegenerative diseases (Kennedy et al., 2014). As $\mathrm{UPR}^{\mathrm{MT}}$ activation extends mitochondrial function, further characterization of the pathway will provide stronger hints to understand neuronal homeostasis and healthspan extension. So far, it seems that UPR ${ }^{\mathrm{MT}}$ activation is partially modulated by the age-dependent methylation levels of Histone 3. As H3K9 is differentially methylated in specific brain regions (Snigdha et al., 2016), regulation of the UPR ${ }^{\mathrm{MT}}$ could differ in distinct neuronal types. This fact raises concerns when thinking about therapeutic approaches since systemic inhibition of $\mathrm{UPR}^{\mathrm{MT}}$ 
could be beneficial for cell types with a dysregulated activation of $\mathrm{UPR}^{\mathrm{MT}}$, but detrimental for another that requires its activation. Therefore, the fine-tuning of UPR ${ }^{\mathrm{MT}}$ in different pathogenic contexts will be a crucial consideration for future studies. In the case of $\mathrm{PD}, \mathrm{AD}$ and ALS, incipient evidence has emerged in the last years highlighting also an over-activation of UPR ${ }^{\mathrm{MT}}$ as contributors of the ND pathomechanisms. Future studies on this topic should focus on determining whether known ND causative genes are associated to $\mathrm{UPR}^{\mathrm{MT}}$ components on an early neurodegenerative stage, or whether $\mathrm{UPR}^{\mathrm{MT}}$ is only activated on a late, non-reversible stage as a consequence of an overall neuronal decay. Precise pharmacological modulation of the mitochondrial stress response could bring new alternatives to restore compromised neuronal functions, with a prospective increase in the life quality of ND patients and the elderly population.

\section{REFERENCES}

Al-Furoukh, N., Ianni, A., Nolte, H., Hölper, S., Krüger, M., Wanrooij, S., et al. (2015). ClpX stimulates the mitochondrial unfolded protein response (UPR ${ }^{\mathrm{mt}}$ ) in mammalian cells. Biochim. Biophys. Acta. 1853, 2580-2591. doi: 10.1016/j. bbamcr.2015.06.016

Anderson, C. J., Bredvik, K., Burstein, S. R., Davis, C., Meadows, S. M., Dash, J., et al. (2019). ALS/FTD mutant CHCHD10 mice reveal a tissue-specific toxic gain-of-function and mitochondrial stress response. Acta Neuropathol. 138, 103-121. doi: 10.1007/s00401-019-01989-y

Bakula, D., and Scheibye-Knudsen, M. (2020). Mitophaging: mitophagy in aging and disease. Front. Cell Dev. Biol. 8:239. doi: 10.3389/fcell. 2020.00239

Beck, J., Mufson, E., and Counts, S. (2016). Evidence for mitochondrial UPR gene activation in familial and sporadic alzheimer's disease. Curr. Alzheimer Res. 13, 610-614. doi: 10.2174/1567205013666151221145445

Benedetti, C., Haynes, C. M., Yang, Y., Harding, H. P., and Ron, D. (2006). Ubiquitin-like protein 5 positively regulates chaperone gene expression in the mitochondrial unfolded protein response. Genetics 174, 229-239. doi: 10.1534/genetics.106.061580

Borrás, C., Gambini, J., López-Grueso, R., Pallardó, F. V., and Viña, J. (2010). Direct antioxidant and protective effect of estradiol on isolated mitochondria. Biochim. Biophys. Acta. 1802, 205-211. doi: 10.1016/j.bbadis.2009.09.007

Bowling, A. C., Schulz, J. B., Brown, R. H. Jr., and Beal, M. F. (1993). Superoxide dismutase activity, oxidative damage and mitochondrial energy metabolism in familial and sporadic amyotrophic lateral sclerosis. J. Neurochem. 61, 2322-2325. doi: 10.1111/j.1471-4159.1993.tb07478.x

Brookes, P. S., Yoon, Y., Robotham, J. L., Anders, M. W., and Sheu, S.-S. (2004). Calcium, ATP and ROS: a mitochondrial love-hate triangle. Am J. Physiol. Cell Physiol. 287, C817-C833. doi: 10.1152/ajpcell.00139.2004

Butterfield, D. A., and Halliwell, B. (2019). Oxidative stress, dysfunctional glucose metabolism and Alzheimer disease. Nat. Rev. Neurosci. 20, 148-160. doi: 10.1038/s41583-019-0132-6

Chen, C., Turnbull, D. M., and Reeve, A. K. (2019). Mitochondrial dysfunction in Parkinson's disease-cause or consequence? Biology 8, 1-26. doi: 10.3390/biology8020038

Chistiakov, D. A., Sobenin, I. A., Revin, V. V., Orekhov, A. N., and Bobryshev, Y. V. (2014). Mitochondrial aging and age-related dysfunction of mitochondria. Biomed. Res. Int. 2014:238463. doi: 10.1155/2014/238463

Choi, S. J., Panhelainen, A., Schmitz, Y., Larsen, K. E., Kanter, E., Wu, M., et al. (2015). Changes in neuronal dopamine homeostasis following 1methyl-4-phenylpyridinium (MPP+) exposure. J. Biol. Chem. 290, 6799-6809. doi: $10.1074 /$ jbc.m114.631556

Cooper, J. F., Machiela, E., Dues, D. J., Spielbauer, K. K., Senchuk, M. M., and Van Raamsdonk, J. M. (2017). Activation of the mitochondrial unfolded protein response promotes longevity and dopamine neuron survival in Parkinson's disease models. Sci. Rep. 7:16441. doi: 10.1038/s41598-017-16637-2

\section{AUTHOR CONTRIBUTIONS}

FM-C and MS planned, researched, and wrote the manuscript.

\section{FUNDING}

This work was supported by Comisión Nacional de Investigación Científica y Tecnológica (CONICYT) Subvención a la instalación a la academia (PAI77180059-MS) and Center for Integrative Biology, Universidad Mayor (FM-C).

\section{ACKNOWLEDGMENTS}

We want to thank Dr. Natalia Salvadores and Dr. Felipe Court for their feedback and comments.

Copeland, J. M., Cho, J., Lo, T., Hur, J. H., Bahadorani, S., Arabyan, T., et al. (2009). Extension of drosophila life span by RNA of the mitochondrial respiratory chain. Curr. Biol. 19, 1591-1598. doi: 10.1016/j.cub.2009.08.016

Couvillion, M. T., Soto, I. C., Shipkovenska, G., and Churchman, L. S. (2016). Synchronized mitochondrial and cytosolic translation programs. Nature 533, 499-503. doi: 10.1038/nature18015

Cui, L., Jeong, H., Borovecki, F., Parkhurst, C. N., Tanese, N., and Krainc, D. (2006). Transcriptional repression of PGC-1alpha by mutant huntingtin leads to mitochondrial dysfunction and neurodegeneration. Cell 127, 59-69. doi: 10.1016/j.cell.2006.09.015

Dillin, A., Hsu, A., Arantes-oliveira, N., Lehrer-graiwer, J., Hsin, H., Fraser, A. G., et al. (2002). Rates of behavior and aging specified by mitochondrial function during development. Science 298, 2398-2402. doi: 10.1126/science. 1077780

Durieux, J., Wolff, S., and Dillin, A. (2011). The cell-non-autonomous nature of electron transport chain-mediated longevity. Cell 144, 79-91. doi: 10.1016/j. cell.2010.12.016

Fiorese, C. J., Schulz, A. M., Lin, Y. F., Rosin, N., Pellegrino, M. W., and Haynes, C. M. (2016). The transcription factor ATF5 mediates a mammalian mitochondrial UPR. Curr. Biol. 26, 2037-2043. doi: 10.1016/j.cub.2016. 06.002

Franco-Iborra, S., Vila, M., and Perier, C. (2018). Mitochondrial quality control in neurodegenerative diseases: focus on Parkinson's disease and huntington's disease. Front. Neurosci. 12:342. doi: 10.3389/fnins.2018.00342

Gariani, K., Menzies, K. J., Ryu, D., Wegner, C. J., Wang, X., Ropelle, E. R., et al. (2016). Eliciting the mitochondrial unfolded protein response by nicotinamide adenine dinucleotide repletion reverses fatty liver disease in mice. Hepatology 63, 1190-1204. doi: 10.1002/hep.28245

Gitschlag, B. L., Kirby, C. S., Samuels, D. C., Gangula, R. D., Mallal, S. A., and Patel, M. R. (2016). Homeostatic responses regulate selfish mitochondrial genome dynamics in C. elegans. Cell Metab. 24, 91-103. doi: 10.1016/j.cmet. 2016.06.008

Gomez, M., and Germain, D. (2019). Cross talk between SOD1 and the mitochondrial UPR in cancer and neurodegeneration. Mol. Cell Neurosci. 98, 12-18. doi: 10.1016/j.mcn.2019.04.003

Hardiman, O., Al-Chalabi, A., Chio, A., Corr, E. M., Logroscino, G., Robberecht, W., et al. (2017). Amyotrophic lateral sclerosis. N. Engl. J. Med. 377. 162-172. doi: 10.1056/NEJMra1603471

Haynes, C. M., and Ron, D. (2010). The mitochondrial UPR - protecting organelle protein homeostasis. J. Cell Sci. 123, 3849-3855. doi: 10.1242/ jcs.075119

Haynes, C. M., Petrova, K., Benedetti, C., Yang, Y., and Ron, D. (2007). ClpP mediates activation of a mitochondrial unfolded protein response in C. elegans. Dev. Cell 13, 467-480. doi: 10.1016/j.devcel.2007.07.016

Hetz, C., Zhang, K., Kaufman, R. J. (2020). Mechanisms, regulation and functions of the unfolded protein response. Nat. Rev. Mol. Cell Biol. doi: 10.1038/s41580020-0250-z 
Horibe, T., and Hoogenraad, N. J. (2007). The chop gene contains an element for the positive regulation of the mitochondrial unfolded protein response. PLoS One 2:e835. doi: 10.1371/journal.pone.0000835

Houtkooper, R. H., Mouchiroud, L., Ryu, D., Moullan, N., Katsyuba, E., Knott, G., et al. (2013). Mitonuclear protein imbalance as a conserved longevity mechanism. Nature 497, 451-457. doi: 10.1038/nature12188

Hu, D., Sun, X., Liao, X., Zhang, X., Zarabi, S., Schimmer, A., et al. (2019). Alpha-synuclein suppresses mitochondrial protease $\mathrm{ClpP}$ to trigger mitochondrial oxidative damage and neurotoxicity. Acta Neuropathol. 137, 939-960. doi: 10.1007/s00401-019-01993-2

Jensen, M. B., and Jasper, H. (2014). Mitochondrial proteostasis in the control of aging and longevity. Cell Metab. 20, 214-225. doi: 10.1016/j.cmet.2014. 05.006

Jensen, M. B., Qi, Y., Riley, R., Rabkina, L., and Jasper, H. (2017). PGAM5 promotes lasting FoxO activation after developmental mitochondrial stress and extends lifespan in Drosophila. eLife 6:e26952. doi: 10.7554/ eLife. 26952

Ji, T., Zhang, X., Xin, Z., Xu, B., Jin, Z., Wu, J., et al. (2020). Does perturbation in the mitochondrial protein folding pave the way for neurodegeneration diseases? Ageing Res. Rev. 57, 100-997. doi: 10.1016/j.arr.2019. 100997

Jin, S. M., and Youle, R. J. (2013). The accumulation of misfolded proteins in the mitochondrial matrix is sensed by PINK1 to induce PARK2/Parkinmediated mitophagy of polarized mitochondria. Autophagy 9, 1750-1757. doi: 10.4161 /auto. 26122

Kaarniranta, K., Kajdanek, J., Morawiec, J., Pawlowska, E., and Blasiak, J. (2018). PGC- $1 \alpha$ protects RPE cells of the aging retina against oxidative stress-induced degeneration through the regulation of senescence and mitochondrial quality control. The significance for AMD pathogenesis. Int. J. Mol. Sci. 19:2317. doi: 10.3390/ijms19082317

Kennedy, B. K., Berger, S. L., Brunet, A., Campisi, J., Cuervo, A. M., Epel, E. S., et al. (2014). Geroscience: linking aging to chronic disease. Cell 159, 709-713. doi: 10.1016/j.cell.2014.10.039

Kenny, T. C., and Germain, D. (2017). From discovery of the CHOP axis and targeting ClpP to the identification of additional axes of the UPR ${ }^{\mathrm{mt}}$ driven by the estrogen receptor and SIRT3. J. Bioenerg. Biomembr. 49, 297-305. doi: $10.1007 / \mathrm{s} 10863-017-9722-\mathrm{z}$

Kenny, T. T., Hart, P., Ragazzi, M., Sersinghe, M., Chipuk, J., Sagar, M. A. K., et al. (2017). Selected mitochondrial DNA landscapes activate the SIRT3 axis of the UPR ${ }^{\mathrm{mt}}$ to promote metastasis. Oncogene $36,4393-4404$. doi: 10.1038/onc. 2017.52

Kim, Y., Zheng, X., Ansari, Z., Bunnell, M. C., Herdy, J. R., Traxler, L., et al. (2018). Mitochondrial aging defects emerge in directly reprogrammed human neurons due to their metabolic profile. Cell Rep. 23, 2550-2558. doi: 10.1016/j.celrep. 2018.04.105

Kowald, A., and Kirkwood, T. B. (2000). Accumulation of defective mitochondria through delayed degradation of damaged organelles and its possible role in the ageing of post-mitotic and dividing cells. J. Theor. Biol. 202, 145-160. doi: 10.1006/jtbi.1999.1046

Lan, J., Rollins, J. A., Zang, X., Wu, D., Zou, L., Wang, Z., et al. (2019). Translational regulation of non-autonomous mitochondrial stress response promotes longevity. Cell Rep. 28, 1050-1062.e6. doi: 10.1016/j.celrep.2019. 06.078

Lin, Y.-F., and Haynes, C. M. (2016). Metabolism and the UPR ${ }^{\mathrm{mt}}$. Mol. Cell 61, 677-682. doi: 10.1016/j.molcel.2016.02.004

Lin, Y.-F., Schulz, A. M., Pellegrino, M. W., Lu, Y., Shaham, S., and Haynes, C. M. (2016). Maintenance and propagation of a deleterious mitochondrial genome by the mitochondrial unfolded protein response. Nature 533, 416-419. doi: 10.1038/nature17989

Lores-Arnaiz, S., Lombardi, P., Karadayian, A. G., Orgambide, F., Cicerchia, D., and Bustamante, J. (2016). Brain cortex mitochondrial bioenergetics in synaptosomes and non-synaptic mitochondria during aging. Neurochem. Res. 41, 353-363. doi: 10.1007/s11064-015-1817-5

Martinez, B. A., Petersen, D. A., Gaeta, A. L., Stanley, S. P., Caldwell, G. A., and Caldwell, K. A. (2017). Dysregulation of the mitochondrial unfolded protein response induces non-apoptotic dopaminergic neurodegeneration in C. elegans models of Parkinson's disease. J. Neurosci. 37, 11085-11100. doi: 10.1523/jneurosci.1294-17.2017
Martinus, R., Garth, G., Webster, T., Cartwright, P., Naylor, D., Høj, P., et al. (1996). Selective induction of mitochondrial chaperones in response to loss of the mitochondrial genome. Eur. J. Biochem. 240, 98-103. doi: 10.1111/j.14321033.1996.0098h.x

Masters, C., Bateman, R., Blennow, K., Rowe, C., Sperling, R., and Cummings, J. (2015). Alzheimer's disease. Nat. Rev. Dis. Prim. 1, 1-18.

Mattiazzi, M., D’Aurelio, M., Gajewski, C. D., Martushova, K., Kiaei, M., Flint Beal, M., et al. (2002). Mutated human SOD1 causes dysfunction of oxidative phosphorylation in mitochondria of transgenic mice. J. Biol. Chem. 277, 29626-29633. doi: 10.1074/jbc.m203065200

Menzies, K. J., Zhang, H., Katsyuba, E., and Auwerx, J. (2016). Protein acetylation in metabolism-metabolites and cofactors. Nat. Rev. Endocrinol. 12, 43-60. doi: 10.1038/nrendo.2015.181

Merkwirth, C., Jovaisaite, V., Durieux, J., Matilainen, O., Jordan, S. D., Quiros, P. M., et al. (2016). Two conserved histone demethylases regulate mitochondrial stress-induced longevity. Cell 165, 1209-1223. doi: 10.1016/j. cell.2016.04.012

Misgeld, T., and Schwarz, T. L. (2017). Mitostasis in neurons: maintaining mitochondria in an extended cellular architecture. Neuron 96, 651-666. doi: 10.1016/j.neuron.2017.09.055

Moisoi, N., Fedele, V., Edwards, J., and Martins, L. M. (2014). Loss of PINK1 enhances neurodegeneration in a mouse model of Parkinson's disease triggered by mitochondrial stress. Neuropharmacology 77, 350-357. doi: 10.1016/j.neuropharm.2013.10.009

Mouchiroud, L., Houtkooper, R. H., Moullan, N., Katsyuba, E., Ryu, D., Cantó, C., et al. (2013). The NAD+/sirtuin pathway modulates longevity through activation of mitochondrial UPR and FOXO signaling. Cell 154, 430-441. doi: 10.1016/j.cell.2013.06.016

Nargund, A. M., Fiorese, C. J., Pellegrino, M. W., Deng, P., and Haynes, C. M. (2015). Mitochondrial and nuclear accumulation of the transcription factor ATFS-1 promotes OXPHOS recovery during the UPR ${ }^{\mathrm{mt}}$. Mol. Cell 58, 123-133. doi: 10.1016/j.molcel.2015.02.008

Nargund, A. M., Pellegrino, M. W., Fiorese, C. J., Baker, B. M., and Haynes, C. M. (2012). Mitochondrial import efficiency of ATFS-1 regulates mitochondrial UPR activation. Science 337, 587-590. doi: 10.1126/science. 1223560

Niedzielska, E., Smaga, I., Gawlik, M., Moniczewski, A., Stankowicz, P., Pera, J., et al. (2016). Oxidative stress in neurodegenerative diseases. Mol. Neurobiol. 53, 4094-4125. doi: 10.1007/s12035-015-9337-5

Obashi, K., and Okabe, S. (2013). Regulation of mitochondrial dynamics and distribution by synapse position and neuronal activity in the axon. Eur. J. Neurosci. 38, 2350-2363. doi: 10.1111/ejn.12263

Olesen, M. A., Torres, A. K., Jara, C., Murphy, M. P., and Tapia-Rojas, C. (2020). Premature synaptic mitochondrial dysfunction in the hippocampus during aging contributes to memory loss. Redox Biol. 34:101558. doi: 10.1016/j.redox. 2020.101558

Ono, T., Kamimura, N., Matsuhashi, T., Nagai, T., Nishiyama, T., Endo, J., et al. (2017). The histone 3 lysine 9 methyltransferase inhibitor chaetocin improves prognosis in a rat model of high salt diet-induced heart failure. Sci. Rep. 7:39752. doi: 10.1038/srep39752

Owusu-Ansah, E., Song, W., and Perrimon, N. (2013). Muscle mitohormesis promotes longevity via systemic repression of insulin signaling. Cell 155, 699-712. doi: 10.1016/j.cell.2013.09.021

Papa, L., and Germain, D. (2011). Estrogen receptor mediates a distinct mitochondrial unfolded protein response. J. Cell Sci. 124, 1396-1402. doi: $10.1242 /$ jcs. 078220

Papa, L., and Germain, D. (2014). SirT3 regulates the mitochondrial unfolded protein response. Mol. Cell Biol. 34, 699-710. doi: 10.1128/MCB.01337-13

Pellegrino, M. W., and Haynes, C. M. (2015). Mitophagy and the mitochondrial unfolded protein response in neurodegeneration and bacterial infection. $B M C$ Biol. 13:22. doi: 10.1186/s12915-015-0129-1

Pérez, M. J., Ivanyuk, D., Panagiotakopoulou, V., Napoli, G. Di, Brunetti, D., Al-Shaana, R. (2020). Loss of function of the mitochondrial peptidase PITRM1 induces proteotoxic stress and alzheimer's disease-like pathology in human cerebral organoids. Mol. Psychiatry. doi: 10.1038/s41380-0200807-4

Pernas, L., and Scorrano, L. (2016). Mito-morphosis: mitochondrial fusion, fission and cristae remodeling as key mediators of cellular 
function. Annu. Rev. Physiol. 78, 505-531. doi: 10.1146/annurev-physiol021115-105011

Pharaoh, G., Sataranatarajan, K., Street, K., Hill, S., Gregston, J., Ahn, B., et al. (2019). Metabolic and stress response changes precede disease onset in the spinal cord of mutant SOD1 ALS mice. Front. Neurosci. 13:487. doi: 10.3389/fnins.2019.00487

Pimenta de Castro, I., Costa, a C., Lam, D., Tufi, R., Fedele, V., Moisoi, N., et al. (2012). Genetic analysis of mitochondrial protein misfolding in Drosophila melanogaster. Cell Death Differ. 19, 1308-1316. doi: 10.1038/cdd.2012.5

Plun-Favreau, H., Klupsch, K., Moisoi, N., Gandhi, S., Kjaer, S., Frith, D., et al. (2007). The mitochondrial protease HtrA2 is regulated by Parkinson's diseaseassociated kinase PINK1. Nat. Cell Biol. 9, 1243-1252. doi: 10.1038/ncb1644

Poewe, W., Seppi, K., Tanner, C. M., Halliday, G. M., Brundin, P., Volkmann, J., et al. (2017). Parkinson disease. Nat. Rev. Dis. Prim. 3, 1-21. doi: $10.1038 /$ nrdp.2017.13

Qureshi, M. A., Haynes, C. M., and Pellegrino, M. W. (2017). The mitochondrial unfolded protein response: signaling from the powerhouse. J. Biol. Chem. 292, 10500-13506. doi: 10.1074/jbc.r117.791061

Rainbolt, T. K., Atanassova, N., Genereux, J. C., and Wiseman, R. L. (2013). Stress-regulated translational attenuation adapts mitochondrial protein import through Tim17A degradation. Cell Metab. 18, 908-919. doi: 10.1016/j.cmet. 2013.11.006

Regitz, C., Fitzenberger, E., Mahn, F. L., Dußling, L. M., and Wenzel, U. (2016). Resveratrol reduces amyloid-beta (A $\beta 1-42)$-induced paralysis through targeting proteostasis in an alzheimer model of Caenorhabditis elegans. Eur. J. Nutr. 55, 741-747. doi: 10.1007/s00394-015-0894-1

Riar, A. K., Burstein, S. R., Palomo, G. M., Arreguin, A., Manfredi, G., and Germain, D. (2017). Sex specific activation of the $E R \alpha$ axis of the mitochondrial UPR (UPR ${ }^{\mathrm{mt}}$ ) in the G93A-SOD1 mouse model of familial ALS. Hum. Mol. Genet. 26, 1318-1327. doi: $10.1093 / \mathrm{hmg} / \mathrm{ddx} 049$

Rosen, D. R., Siddique, T., Patterson, D., Figlewicz, D. A., Sapp, P., Hentati, A., et al. (1993). Mutations in $\mathrm{Cu} / \mathrm{Zn}$ superoxide dismutase gene are associated with familial amyotrophic lateral sclerosis. Nature 362, 59-62. doi: 10.1038/362059a0

Runkel, E. D., Liu, S., Baumeister, R., and Schulze, E. (2013). Surveillance-activated defenses block the ROS-induced mitochondrial unfolded protein response. PLoS Genet. 9:e1003346. doi: 10.1371/journal.pgen.1003346

Snigdha, S., Prieto, G. A., Petrosyan, A., Loertscher, B. M., Dieskau, A. P., Overman, L. E., Overman, L. E., et al. (2016). H3K9me3 inhibition improves memory, promotes spine formation and increases BDNF levels in the aged hippocampus. J. Neurosci. 36, 3611-3622. doi: 10.1523/jneurosci.2693-15.2016

Shen, Y., Ding, M., Xie, Z., Liu, X., Yang, H., Jin, S., et al. (2020). Activation of mitochondrial unfolded protein response in SHSY5Y expressing APP cells and APP/PS1 mice. Front. Cell Neurosci. 13:568. doi: 10.3389/fncel.2019.00568

Shpilka, T., and Haynes, C. M. (2018). The mitochondrial UPR: mechanisms, physiological functions and implications in ageing. Nat. Rev. Mol. Cell Biol. doi: $10.1038 / \mathrm{nrm} .2017 .110$

Sobue, S., Inoue, C., Hori, F., Qiao, S., Murate, T., and Ichihara, M. (2017). Molecular hydrogen modulates gene expression via histone modification and induces the mitochondrial unfolded protein response. Biochem. Biophys. Res. Commun. 493, 318-324. doi: 10.1016/j.bbrc.2017.09.024

Strauss, K. M., Martins, L. M., Plun-Favreau, H., Marx, F. P., Kautzmann, S., Berg, D., et al. (2005). Loss of function mutations in the gene encoding Omi/HtrA2 in Parkinson's disease. Hum. Mol. Genet. 14, 2099-2111. doi: $10.1093 / \mathrm{hmg} / \mathrm{ddi} 215$

Sugeno, N., Jäckel, S., Voigt, A., Wassouf, Z., Schulze-Hentrich, J., and Kahle, P. J. (2016). $\alpha$-synuclein enhances histone H3 lysine-9 dimethylation and H3K9me2-dependent transcriptional responses. Sci. Rep. 6:36328. doi: $10.1038 /$ srep 36328

Teperino, R., Schoonjans, K., and Auwerx, J. (2010). Histone methyl transferases and demethylases; can they link metabolism and transcription? Cell Metab. 12, 321-327. doi: 10.1016/j.cmet.2010.09.004

Terman, A., Kurz, T., Navratil, M., Arriaga, E. A., and Brunk, U. T. (2010). Mitochondrial turnover and aging of long-lived postmitotic cells: the mitochondrial-lysosomal axis theory of aging. Antioxid. Redox Signal. 12, 503-535. doi: 10.1089/ars.2009.2598
Teske, B. F., Fusakio, M. E., Zhou, D., Shan, J., McClintick, J. N., Kilberg, M. S., et al. (2013). CHOP induces activating transcription factor 5 (ATF5) to trigger apoptosis in response to perturbations in protein homeostasis. Mol. Biol. Cell 24, 2477-2490. doi: 10.1091/mbc.e13-01-0067

Tian, Y., Garcia, G., Bian, Q., Steffen, K. K., Joe, L., Wolff, S., et al. (2016). Mitochondrial stress induces chromatin reorganization to promote longevity and UPR ${ }^{\mathrm{mt}}$. Cell 165, 1197-1208. doi: 10.1016/j.cell.2016.04.011

Tran, H. C., and Van Aken, O. (2020). Mitochondrial unfolded proteinrelated responses across kingdoms: similar problems, different regulators. Mitochondrion 53, 166-177. doi: 10.1016/j.mito.2020.05.009

Tufi, R., Gandhi, S., De Castro, I. P., Lehmann, S., Angelova, P. R., Dinsdale, D., et al. (2014). Enhancing nucleotide metabolism protects against mitochondrial dysfunction and neurodegeneration in a PINK1 model of Parkinson's disease. Nat. Cell Biol. 16, 157-166. doi: 10.1038/ncb2901

Unal Gulsuner, H., Gulsuner, S., Mercan, F. N., Onat, O. E., Walsh, T., Shahin, H., et al. (2014). Mitochondrial serine protease HTRA2 p.G399S in a kindred with essential tremor and parkinson disease. Proc. Natl. Acad. Sci. U S A 111, 18285-18290. doi: 10.1073/pnas.1419581111

Wallace, D. C., and Chalkia, D. (2013). Mitochondrial DNA genetics and the heteroplasmy conundrum in evolution and disease. Cold Spring Harb. Perspect Biol. 5:a021220. doi: 10.1101/cshperspect.a021220

Wang, P., Deng, J., Dong, J., Liu, J., Bigio, E. H., Mesulam, M., et al. (2019). TDP43 induces mitochondrial damage and activates the mitochondrial unfolded protein response. PLoS Genet. 15:e1007947. doi: 10.1371/journal.pgen. 1007947

Weidling, I. W., and Swerdlow, R. H. (2020). Mitochondria in alzheimer's disease and their potential role in alzheimer's proteostasis. Exp. Neurol. 330:113321. doi: 10.1016/j.expneurol.2020.113321

Wu, Z., Senchuk, M. M., Dues, D. J., Johnson, B. K., Cooper, J. F., Lew, L., et al. (2018). Mitochondrial unfolded protein response transcription factor ATFS-1 promotes longevity in a long-lived mitochondrial mutant through activation of stress response pathways. BMC Biol. 16:147. doi: 10.1186/s12915-0180615-3

Yano, M. (2017). ABCB10 depletion reduces unfolded protein response in mitochondria. Biochem. Biophys. Res. Commun. 486, 465-469. doi: 10.1016/j. bbrc.2017.03.063

Yoneda, T., Benedetti, C., Urano, F., Clark, S. G., Harding, H. P., and Ron, D. (2004). Compartment-specific perturbation of protein handling activates genes encoding mitochondrial chaperones. J. Cell Sci. 117, 4055-4066. doi: 10.1242/jcs.01275. Epub 2004 Jul 27

Yuan, J., Chang, S., Yin, S., Liu, Z., Cheng, X., and Liu, X. (2020). Two conserved epigenetic regulators prevent healthy ageing. Nature 579, 118-122. doi: 10.1038/s41586-020-2037-y

Zhang, B., Gaiteri, C., Bodea, L. G., Wang, Z., McElwee, J., Podtelezhnikov, A. A., et al. (2013). Integrated systems approach identifies genetic nodes and networks in late-onset alzheimer's disease. Cell 153, 707-720. doi: 10.1016/j.cell. 2013.03.030

Zhao, Q., Wang, J., Levichkin, I. V., Stasinopoulos, S., Ryan, M. T., and Hoogenraad, N. J. (2002). A mitochondrial specific stress response in mammalian cells. EMBO J. 21, 4411-4419. doi: 10.1093/emboj/cdf445

Zhu, J.-Y., Vereshchagina, N., Sreekumar, V., Burbulla, L. F., Costa, A. C., Daub, K. J., et al. (2013). Knockdown of Hsc70-5/mortalin induces loss of synaptic mitochondria in a Drosophila Parkinson's disease model. PLoS One 8:e83714. doi: 10.1371/journal.pone.0083714

Conflict of Interest: The authors declare that the research was conducted in the absence of any commercial or financial relationships that could be construed as a potential conflict of interest.

Copyright (๑) 2020 Muñoz-Carvajal and Sanhueza. This is an open-access article distributed under the terms of the Creative Commons Attribution License (CC BY). The use, distribution or reproduction in other forums is permitted, provided the original author(s) and the copyright owner(s) are credited and that the original publication in this journal is cited, in accordance with accepted academic practice. No use, distribution or reproduction is permitted which does not comply with these terms. 